\title{
CASE SERIES OF FEMORAL SHAFT FRACTURES INNOVATIVELY MANAGED BY USING REAMED MATERIAL AS INTERNAL BONE GRAFT FOR EARLY FRACTURE UNION
}

\author{
Palanimalai Vijayakumar1, Kolundan Kalyanasundaram², Anbu Srinivasan³, Pulavan Ibrahim Raja Ashiq Ali ${ }^{4}$ \\ ${ }^{1}$ Assistant Professor, Department of Orthopaedics, KAP Viswanatham Government Medical College/MGM Govt. Hospital, Tiruchirapalli. \\ ${ }^{2}$ Associate Professor, Department of Orthopaedics, KAP Viswanatham Government Medical College/MGM Govt. Hospital, Tiruchirapalli. \\ ${ }^{3}$ Associate Professor, Department of Orthopaedics, KAP Viswanatham Government Medical College/MGM Govt. Hospital, Tiruchirapalli. \\ ${ }^{4}$ Assistant Professor, Department of Orthopaedics, KAP Viswanatham Government Medical College/MGM Govt. Hospital, Tiruchirapalli.
}

ABSTRACT

\section{BACKGROUND}

Femur fracture treatment has constantly evolved over time from various conservative methods to various newer modalities of fixation. Since the incidence of malunion and non-union in conservative methods was more, gradually the treatment shifted to fixation as the primary mode of treatment. After IM nailing was introduced it has almost become a gold standard for femur fracture fixation. Reaming femoral canal is an integral part of nailing procedure. Previously, reamed material which stuck to the reamers were often ignored and neglected. Hence, recent interest has been in the judicial use of reamed material obtained through reaming. We thought if we could accumulate the reamed material in the fracture site, even with closed nailing, we could achieve the objective of using this potential bone graft material effectively. At this juncture, we have devised this new idea of reaming the proximal femoral canal before reducing the fracture, thereby depositing the reamed material in the fracture site and studied the effect.

\section{MATERIALS AND METHODS}

This is a case series study carried out in KAP Viswanatham Government Medical College/MGM Government Hospital, Trichy from 2013 to 2016 of 40 cases of femoral shaft fractures satisfying inclusion/exclusion criteria. Entry portal created as in any other standard nailing procedure and after entry portal is made, we did not pass the guide wire into the distal fragment and did not reduce the fracture. Instead, the fracture was left as it is and the guide wire was passed up to the fracture site only. Instead of using routine cutting reamers, we used a slightly modified reamer. Serial reaming was done until the fracture site was reached and up to the maximum size. Then as per standard IM nailing technique, appropriate-sized nail was inserted and locked.

\section{RESULTS}

Bridging bony callus was visible in $4-6$ weeks in 22 cases of which 17 were simple and 5 comminuted. They subsequently united radiologically in 8 - 10 weeks and complete union seen in $10-12$ weeks. In the rest 18 cases, bony callus was visible in $6-8$ weeks. These 18 patients had radiological union in $10-12$ weeks and complete union in 12 - 14 weeks. In our study, all 40 cases went for complete union.

\section{CONCLUSION}

In our study, all 40 cases united well clinically and radiologically. And we also noted that there was early union occurring in all 40 cases. There was no incidence of non-union in our study. We advocate this simple modification in reamer and the reaming technique to obtain early union in femoral shaft fractures. Hence, we conclude this is a useful and safe mode of fixing femoral shaft fractures to avoid potential second surgery for grafting.

\section{KEYWORDS}

Intramedullary Reamed Material, Early Union, Femur Fracture, Internal Bone Grafting.

HOW TO CITE THIS ARTICLE: Vijayakumar P, Kalyanasundaram K, Srinivasan A, et al. Case series of femoral shaft fractures innovatively managed by using reamed material as internal bone graft for early fracture union. J. Evolution Med. Dent. Sci. 2017;6 (42):3337-3343, DOI: $10.14260 / J e m d s / 2017 / 723$

\section{BACKGROUND}

Femur fracture treatment has constantly evolved over time from various conservative methods to various newer modalities of fixation. Since the incidence of malunion and non-union in conservative methods was more, gradually the

Financial or Other, Competing Interest: None.

Submission 18-04-2017, Peer Review 13-05-2017,

Acceptance 18-05-2017, Published 25-05-2017.

Corresponding Author:

Dr. Kolundan Kalyanasundaram,

A1-F1, Rohini Garden Enclave,

Pattabiraman Street,

Tennur, Trichy-600017.

E-mail: kalyanortho@yahoo.co.in

DOI: $10.14260 /$ jemds $/ 2017 / 723$ treatment shifted to fixation as the primary mode of treatment. After IM nailing was introduced it has almost become gold standard for femur fracture fixation. ${ }^{1-4}$ Even in nailing, various methods and techniques have evolved. Initially it was open nailing and then after fluoroscopy was introduced, closed nailing has become the standard. But even in closed nailing where the fracture haematoma was not disturbed, there was significant chance of non-union occurring. It has always been a race between bony union and implant failure and subsequent non-union. To treat nonunion, a secondary procedure viz. bone grafting had to be carried out which significantly increases morbidity and the union time. In some cases, exchange nailing had to be carried out to treat non-union. So now the interest is in promoting early union of fractures before implant failure sets in. 
Everyday a new technique or a variation of old technique is tried to promote or hasten bone union without the requirement of a secondary procedure.

Reaming femoral canal is an integral part of nailing procedure. Previously, reamed material which stuck to the reamers were often ignored and neglected. Various studies of reamed material obtained with techniques like RIA proved that the reamed material is as good as iliac crest bone graft both in quantity and quality. Inducing membrane techniques used the reamed material effectively in treating gap of nonunions of long bones. Hence, recent interest has been in the judicial use of reamed material obtained through reaming. It is in this context we started studying how reamed material could be used effectively even in primary surgery to hasten union avoiding secondary grafting procedure. We have noticed that when fracture is reduced by closed means and then reamed, the reamed material either stays in the femoral canal or is being sucked out during irrigation and suction. So, this precious material is being lost and the potentiality to hasten union is gone. We thought if we could accumulate the reamed material in the fracture site, even with closed nailing, we could achieve the objective of using this potential bone graft material effectively. At this juncture, we have devised this new idea of reaming the proximal femoral canal before reducing the fracture, thereby depositing the reamed material in the fracture site and studied the effect.

\section{MATERIALS AND METHODS}

This is a case series study carried out in KAP Viswanatham Government Medical College/MGM Government Hospital, Trichy from 2013 to 2016 of 40 cases of femoral shaft fractures satisfying the following criteria:

\section{Inclusion Criteria}

- Age group 20 - 50 years.

- Closed femoral shaft fractures either simple or comminuted.

\section{Exclusion Criteria}

- Open fractures

- Shaft fractures extending into proximal and distal metaphysis

- Segmental fractures

- Pathological fractures

- Associated chest injuries

- Associated co-morbid conditions, Diabetes, immunocompromised state

- $\quad$ Chain smokers (Because they are prone for non-union)

All the cases were subjected to routine evaluation for surgery. X-rays were taken in AP and lateral views.

All cases were done under spinal anaesthesia and under C-arm Control. Patients were placed in supine position in fracture table. Contralateral limb was placed in lithotomy position. Entry portal created as in any other standard nailing procedure and after entry portal is made, we did not pass the guide wire into the distal fragment and did not reduce the fracture. Instead, the fracture was left as it is and the guide wire was passed up to the fracture site only. Instead of using routine cutting reamers, we used a slightly modified reamer by tweaking the reamer design by making the flutes straight (just like in the proximal entry reamer) instead of them being spiral. This design modification helps in pushing the reamed material into the canal. By this we ensured that the reamed materials are pushed into the fracture site rather than sticking to the reamer and the femoral canal as it normally happens with the standard reamers. Serial reaming was done until the fracture site was reached and up to the maximum size i.e. in our study, $1 \mathrm{~mm}$ above isthmus diameter as determined by preoperative planning. Proximal entry reaming with the reamer size equalling the proximal nail diameter is done at this juncture itself. This ensures that the abundant metaphyseal reamed material is pushed into the fracture site. Maximum reamed debris is obtained from the proximal metaphyseal reaming. Part of the reamed material which sticks to the reamer blade flutes is collected in a bowl. Reamed material that sticks to the proximal larger diameter of entry reamer is also collected into the bowl. The collected material is normally very dense. To aerate the reamed material, it is spread over a kidney dish and spread with a curette. Now this reamed debris is collected and is pushed into a larger diameter sleeve (locking drill sleeve can be used) and the sleeve is inserted into the entry site. With the trocar, the reamed material in the sleeve is pushed into the medullary canal. The maximum size reamer which was used to ream the femoral canal before proximal entry reamer, is again inserted up to the fracture site to push the reamed material into the fracture site. (Smaller size reamers fail to push the reamed material into the fracture site satisfactorily). We observed that by this technique, the reamed material is pushed out into the fracture site. $\mathrm{C}$-arm image at this juncture shows the presence of abundant reamed material in the fracture site vicinity. Then the thigh is gently rolled to and fro to evenly distribute the reamed material around the fracture site. This will ensure that the reamed material mixes with the fracture haematoma around the fracture.

After this the fracture is reduced and standard nailing procedure is started; guide wire passed and serial reaming of the distal fragment is done. Then, as per standard IM nailing technique, appropriate-sized nail is inserted and locked.

Parenteral antibiotics, usually third generation cephalosporins, were used for three days. DVT prophylaxis is initiated. Rehabilitation is started immediately. Static quadriceps exercise and knee ROM started a day after surgery. Toe touch and touchdown walking started as and when tolerable. Partial weightbearing started when callus was visible radiologically and full weightbearing initiated when patient had no pain and radiologically union was visible.

\section{RESULTS}

40 cases of femoral shaft fractures, either simple or comminuted satisfying the inclusion criteria, were fixed with IM nail as per the procedure described above. Patients were followed up at 4, 6, 8, 10,12,14, 16, 20, 24 weeks, 1 year and 2 years' duration. During follow-up, x-rays were taken. The fracture was deemed to be united radiologically when at least three cortices in two different views were united. Complete union is defined as when radiological union has occurred and the patient can fully return to his activities without pain.

Age distribution in our study was 22 - 50 years. Average age was 36 years. 30 cases were male and 10 cases were female. Majority of the cases were due to RTA followed by fall from height. 25 cases were right-sided injuries 15 were left- 
sided injuries. There were no bilateral femur fractures in our study. 18 cases were simple fractures and 22 cases were comminuted fractures. All cases were operated under same protocol. Bridging bony callus was visible in $4-6$ weeks in 22 cases of which 17 were simple and 5 comminuted. They subsequently united radiologically in $8-10$ weeks and complete union in $10-12$ weeks. In the rest 18 cases, bony callus was visible in $6-8$ weeks. These 18 patients had radiological union in $10-12$ weeks and complete union in 12 - 14 weeks. In our study, all 40 cases went for complete union. There was no incidence of non-union in our study. Successful outcome of fracture fixation was defined as one which went for complete union without the necessity of a secondary procedure. Pain score was analysed at 6 months' duration, and patients with no pain at this examination and who have returned to their original activities were deemed to have successful outcome.

We noted the following complications in our study. Superficial infection was noted in one case which healed with extended antibiotic coverage. Two patients developed thigh pain which might be due to the tension developed in the thigh compartment caused by the accumulation of reamed material along with the fracture haematoma. No case required secondary grafting procedure.

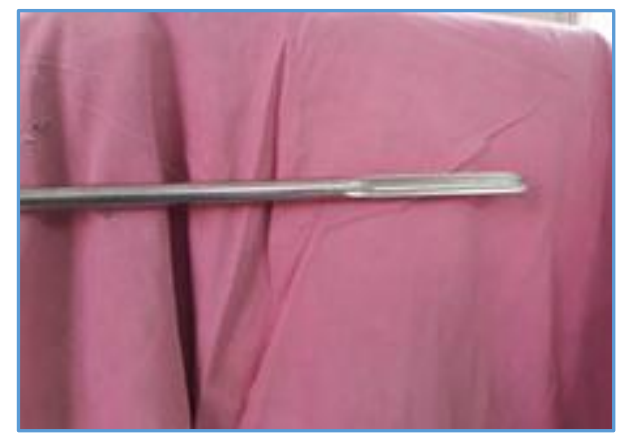

Figure 1. Modified Innovative Reamer (with long straight flutes)

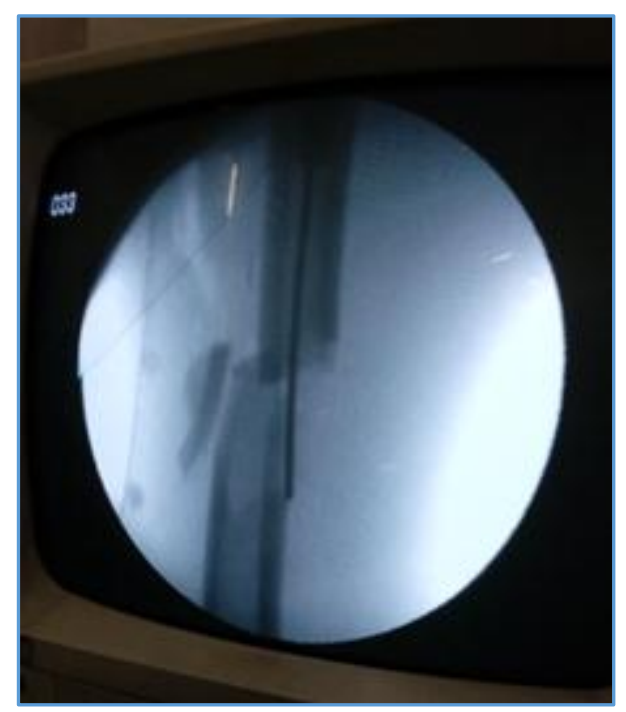

Figure 2. Guide Wire Insertion up to Fracture Site

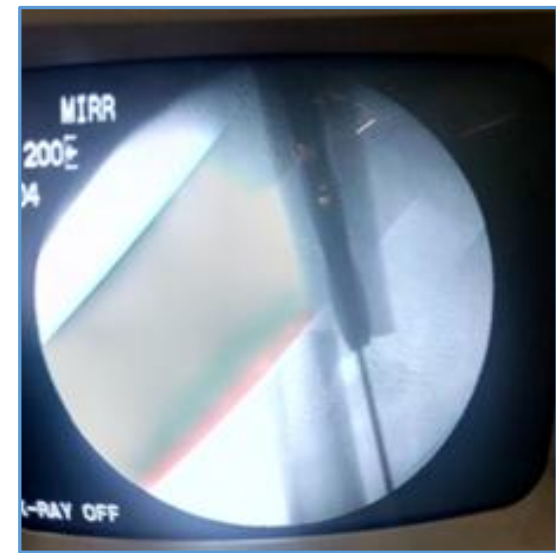

Figure 3. Proximal Reaming

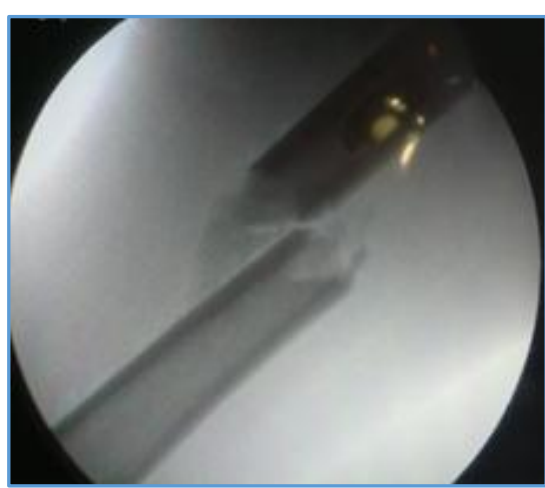

Figure 4. C-Arm Image Showing Reamed Material at Fracture Site

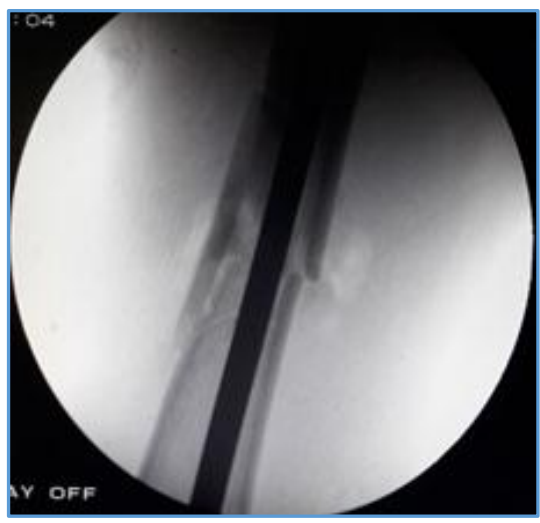

Figure 5. Reamed Material at Fracture Site (after nail insertion)

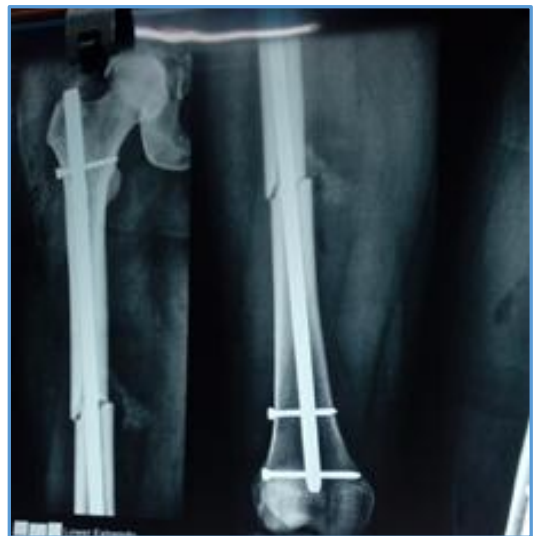

Figure 6. Case 1, Immediate Post-op 


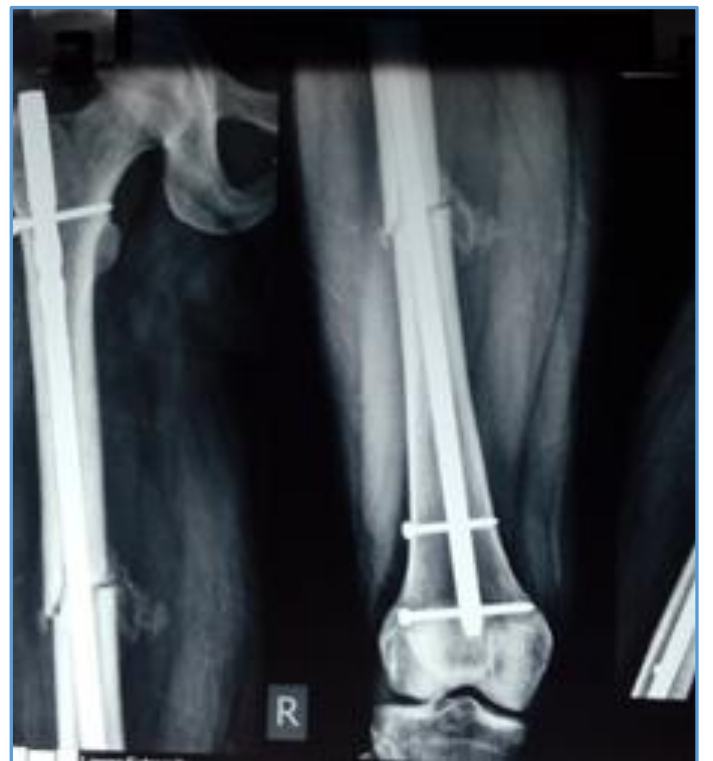

Figure 7. Case 1, Four weeks Follow-up

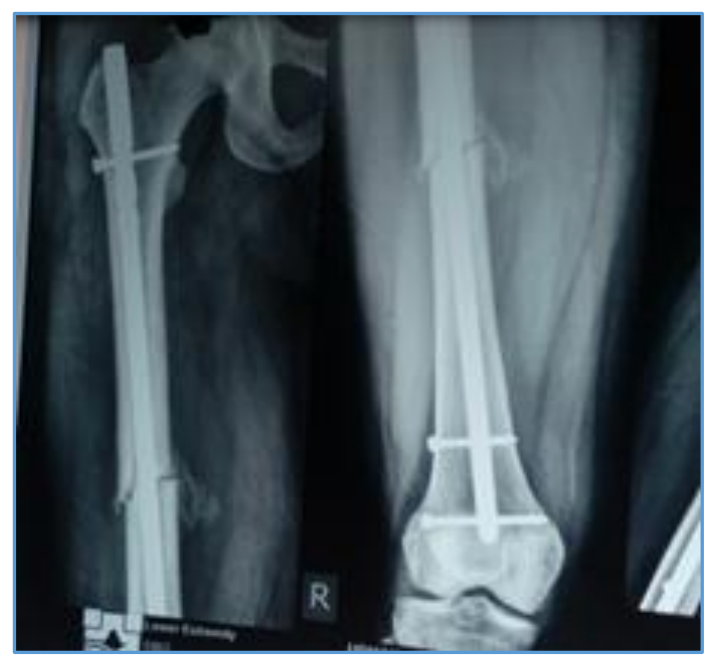

Figure 8. Case 1, Six weeks Follow-up

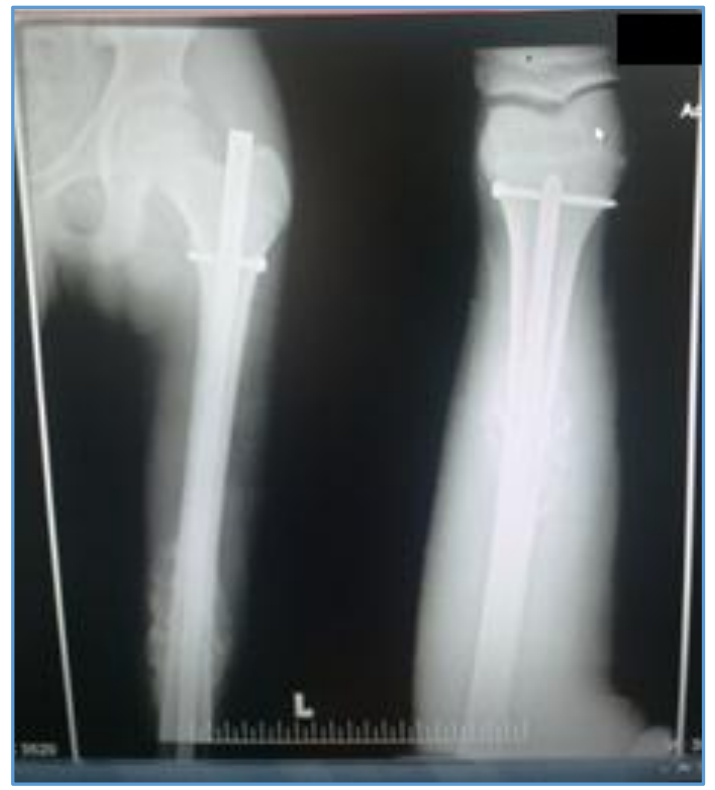

Figure 9. Case 2, Six weeks Follow-up

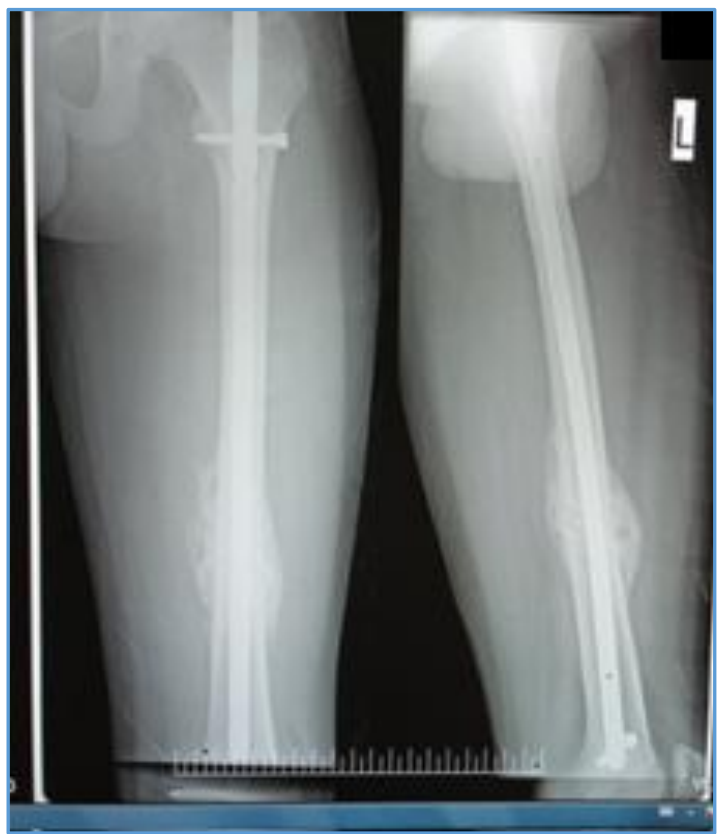

Figure 10. Case 2, Eight weeks Follow-up

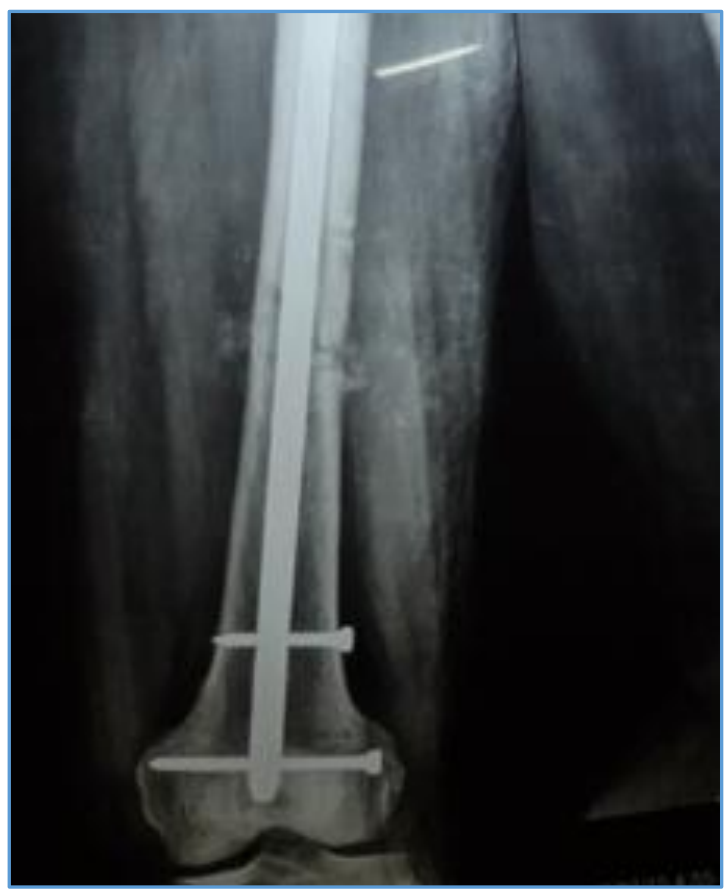

Figure 11. Case 3, Four weeks Post-op

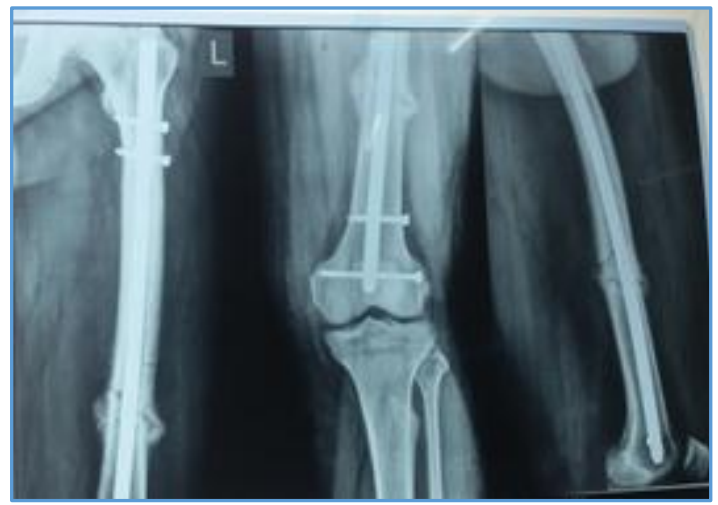

Figure 12. Case 3, Eight weeks Post-op 


\section{DISCUSSION}

Fracture healing is a complex biological process involving cellular response for bone formation which requires mechanical stability, adequate blood supply and good bony apposition. ${ }^{5}$

The most productive source of cells that influence osteogenesis is considered to be autologous marrow. Healing response is affected by the severity of the injury i.e. open fractures, ${ }^{6,7}$ suboptimal surgical fixation and a combination of other indirect factors such as infection, ${ }^{6}$ smoking, ${ }^{7-9}$ excessive use of NSAIDS, 10 diabetes mellitus, ${ }^{6,7,11}$ delay in onset of treatment and initial modality of treatment ${ }^{12}$ which can predispose to delayed union/non-union of long bone fractures.

The literature contains numerous reports regarding reaming debris and its inherent qualities that make it a potential source of autologous bone graft. ${ }^{13-20}$ Reaming debris has been well studied and in many studies, they have shown that the osteocytes and osteoblasts in the reaming debris are viable, with presence of growth factors which are known to participate in the various phases of fracture-healing and bone formation. The use of reaming debris as a source of autologous bone graft is further supported by a number of studies showing that bone material collected from reaming retains osteocyte viability as well as the presence of biochemical proteins known to stimulate bonehealing. ${ }^{14,15,17,21}$ The intramedullary reaming debris has an abundance of progenitor cells and growth factors. ${ }^{21-24}$ Various papers establish that the benefit from reamed particles is the existence of viable osteoprogenitors within the bone matrix itself, not merely in the marrow, which is well accepted.15,21,24,25 Quantitative analysis of the reaming debris have found higher levels of fibroblast growth factor (FGFa), platelet-derived growth factor (PDGF), insulin like growth factor (IGF)-1, BMP-2, and transforming growth factor (TGF)b1 which play a vital role in osteosynthesis. ${ }^{16}$ Wenisch and colleagues ${ }^{21}$ studied human reaming debris using cell cultures and found multipotent stem cells capable of differentiating along the osteogenic pathway.

Macroscopically, the reamed debris material consisted of slurry of very small bone fragments mixed with blood clot, and was similar to those of a fluid or semisolid in consistency. Histological analysis at lower magnifications of the reamed debris contained smaller bone fragments with a greater content of haematopoietic elements. At higher magnifications, the reamed debris contained a mixture of small cancellous and cortical bone fragments, with the latter types of bone containing many haversian elements. In addition, the reamed debris also contained fragments of intact vascular tissue having the appearance of small arterioles. The reamed debris samples composed of smaller bone fragments and dissociated hematopoietic tissue.

PCR analysis has demonstrated the potential osteogenic and osteoinductive properties of the reaming debris. ${ }^{13,14,16,17,26}$ Recent studies have showed that angiogenic factors were decreased and growth factors were increased in the RIA samples (which is essentially reamed debris). ${ }^{16,26}$ Various studies $15,17,26$ have corroborated that viable osteocytes and osteoprogenitor cells are present in the reamed material. Sagi et $\mathrm{al}^{26}$ analysis suggests that the RIA samples had a greater enrichment in mesenchymal stem cells.
Sagi et $\mathrm{al}^{26}$ and Cox et $\mathrm{al}^{27}$ showed that reamed debris had a greater percentage of colony-forming fibroblastic cells.

It is possible to collect 20 to $30 \mathrm{cc}$ volume of bone debris by reaming the medullary canal at the isthmus of the femur. Increasing the reamer size by $1 \mathrm{~mm}$ over the isthmus size will double the collected bone debris volume. Over-reaming the canal by $2 \mathrm{~mm}$ will generally produce between 80 and $90 \mathrm{cc}$ of cortical-cancellous bone graft material. The collected material is extremely dense with "moist sand" like consistency. ${ }^{23}$

Another benefit of intramedullary canal bone graft is that it is harvested using a reamer which is an inherent procedure of fixation. Tuli et $\mathrm{al}^{25}$ performed a study on harvesting progenitor cells from trabecular bone. The femoral head from the same patient undergoing total hip arthroplasty was reamed using an acetabular reamer, but bone was also harvested from the same femoral head using a curette and then minced. Not only did the cells from the reaming proliferate in vitro more rapidly than the cells harvested using a curette, but there were also a significantly larger number of cells in the cultures of the reamed vs. the curetted cells. The study attributed this finding to the smaller and finer bone fragments generated by the reamer, which resulted in a release of more multipotential stromal cells from the trabecular bone.

Autograft materials are usually well enriched with the presence of viable cells, are nonimmunogenic, have greater osteoinductivity and osteoconductivity ${ }^{28}$ and are usually well incorporated and less extensively resorbed over time than allografts because of their nonimmunogenic characteristics. There is always the risk of potential of disease transmission in cadaveric allografts, ${ }^{29-32}$ but this risk is absent in the use of autologous bone graft. Although autologous bone graft from the iliac crest continues to be the gold standard, it has the distinct disadvantages of donor site morbidity and limited volume (approximately20 to $50 \mathrm{~cm}^{3}$ ). The rate of major complications in iliac crest bone grafting can go as high as $25 \%$, and the rate of minor complications ranges as high as $39 \%{ }^{33,34}$ Goulet et al reported major complications in $2.4 \%$ of patients and minor complications in $21.8 \%$. Pain was the most frequent complaint in the first six months after surgery (in $38 \%$ of patients), with $19 \%$ of patients continuing to report pain at more than two years postoperatively. ${ }^{35}$

The morbidity associated with iliac crest bone graft harvesting makes alternative methods of obtaining autograft attractive to orthopaedic surgeons and patients. Reamed medullary debris has a greater enrichment in mesenchymal stem cells than the iliac crest bone graft on the basis of both greater expression of specific human mesenchymal stem cell markers such as $\mathrm{CD} 146^{36}$ and greater expression of BMP receptors. ${ }^{37}$ Such findings are also consistent with those of Cox et al who showed that RIA samples (which are similar to reamed debris) had a greater percentage of colony-forming fibroblastic cells. Reamed debris has greater regenerative characteristics compared with iliac crest bone graft including the similarity of the gene expression profiles in the RIA tissues to expression profiles in experimental models of bone-healing after marrow reaming inrats ${ }^{38}$ and during fracture-healing in mice. ${ }^{37}$

The reamed debris was pushed into the canal and wasted or the reamed debris stuck to the reamers and wasted or the reamed debris was pasted along the femoral canal and 
wasted in previous techniques of reducing the femoral shaft fracture first and then serial reaming of the femur. In one of the abovementioned ways, about $60 \mathrm{cc}$ of potential graft material was lost due to the ignorance of the benefit of the reamed debris. RIA and Masquelet technique created a curiosity in us to devise new means to avoid wasting the potential graft material in most economical and reproducible means. We tweaked the reamer design by keeping the flutes straight and also changed the way the femur fractures were reamed. Instead of reducing first and reaming later, we reamed up to the fracture site first thereby ensuring the accumulation of the reaming debris in the fracture site. This will ensure that the potential graft material stays at the fracture site after fixation and thereby avoiding grafting procedures in late stages.

\section{CONCLUSION}

Ours was a case series study of 40 cases of femoral shaft fractures operated by this new modification of reaming. In our study, all 40 cases united well clinically and radiologically. And we also noted that there was early union occurring in all 40 cases. Bridging bony callus was visible in 4 - 6 weeks in 22 cases of which 17 were simple and 5 comminuted. They subsequently united radiologically in 8 10 weeks and complete union in $10-12$ weeks. In the rest 18 cases, bony callus was visible in $6-8$ weeks. These 18 patients had radiological union in $10-12$ weeks and complete union in 12 - 14 weeks. There was no incidence of non-union in our study. We advocate this simple modification in reamer and the reaming technique to obtain early union in femoral shaft fractures. There is no extra expenditure by modifying the reamer as well as this technique is easy to reproduce. By this technique, we could avoid wasting of the potential graft material and also avoid secondary procedures like grafting, exchange nailing, etc. Hence, we conclude this is a useful and safe mode of fixing femoral shaft fractures to avoid potential second surgery for grafting.

\section{REFERENCES}

[1] Taitsman LA, Lynch JR, Agel J, et al. Risk factors for femoral nonunion after femoral shaft fracture. J Trauma 2009;67(6):1389-92.

[2] Canadian Orthopaedic Trauma Society. Non-union following intramedullary nailing of the femur with and without reaming. Results of a multicenter randomized clinical trial. J Bone Joint Surg Am 2003;85-A(11): 2093-6.

[3] Wolinsky PR, McCarty E, Shyr Y, et al. Reamed intramedullary nailing of the femur: 551 cases. J Trauma 1999;46(3):392-9.

[4] Ostrum RF, DiCicco J, Lakatos R, et al. Retrograde intramedullary nailing of femoral diaphyseal fractures. J Orthop Trauma 1998;12(7):464-8.

[5] Kundar R, Pandey PK. Comparison of two techniques of reaming for delayed-union long bone fractures of lower limb - a new innovative technique. Global Journal for Research Analysis 2016;5(2):201-3.

[6] Frey C, Halikus NM, Vu-Rose T, et al. A review of ankle arthrodesis: predisposing factors to nonunion. Foot Ankle Int 1994;15(11):581-4.
[7] Perlman MH, Thordarson DB. Ankle fusion in a high risk population: an assessment of nonunion risk factors. Foot Ankle Int 1999;20(8):491-6.

[8] Schmitz MA, Finnegan M, Natarajan R, et al. Effect of smoking on tibial shaft fracture healing. Clin Orthop Relat Res 1999;365:184-200.

[9] Harvey EJ, Agel J, Selznick HS, et al. Deleterious effect of smoking on healing of open tibia-shaft fractures. Am J Orthop (Belle Mead NJ) 2002;31(9):518-21.

[10] Giannoudis PV, MacDonald DA, Matthews SJ, et al. Nonunion of the femoral diaphysis. The influence of reaming and non-steroidal anti-inflammatory drugs. J Bone Joint Surg Br 2000;82(5):655-8.

[11] Kayal RA, Tsatsas D, Bauer MA, et al. diminished bone formation during diabetic fracture healing is related to the premature resorption of cartilage associated with increased osteoclast activity. Journal of Bone and Mineral Research 2007;22(4):560-8.

[12] Kumar MS, Indu D, Asha KP, et al. Factors associated with delayed union of long bones - a case control study. Kerala Journal of Orthopaedics 2014;27(1):6-9.

[13] Fr"olke JP, Bakker FC, Patka P, et al. Reaming debris in osteotomized sheep tibiae. J Trauma 2001;50(1):6570.

[14] Frolke JP, Nulend JK, Semeins CM, et al. Viable osteoblastic potential of cortical reamings from intramedullary nailing. J Orthop Res 2004;22(6):12715.

[15] Hoegel F, Mueller CA, Peter R, et al. Bone debris: dead matter or vital osteoblasts. J Trauma 2004;56(2):3637.

[16] Schmidmaier G, Herrmann S, Green J, et al. Quantitative assessment of growth factors in reaming aspirate, iliac crest, and platelet preparation. Bone 2006;39(5):1156-63.

[17] Tydings JD, Martino LJ, Kircher M, et al. Viability of intramedullary canal bone reamings for continued calcification. Am J Surg 1987;153(3):306-9.

[18] Zucman J, Maurer P, Berbesson C. Experimental study of osteogenic action of periosteal grafts, bone marrow grafts and centro-medullary riming. Rev Chir Orthop Reparatrice Appar Mot 1968;54(3):221-38.

[19] Chapman MW. Closed intramedullary bone grafting and nailing of segmental defects of the femur. J Bone Joint Surg Am 1980;62(6):1004-8.

[20] Tydings JD, Martino LJ, Kircher $M$, et al. The osteoinductive potential of intramedullary canal bone reamings. Curr Surg 1986;43(2):121-4.

[21] Wenisch S, Trinkaus K, Hild A, et al. Human reaming debris: a source of multipotent stem cells. Bone 2005;36(1):74-83.

[22] Hak DJ, Pittman JL. Biological rationale for the intramedullary canal as a source of autograft material. Orthopedic Clinics of North America 2010;41(1): 57-61.

[23] Masquelet AC, Benko PE, Mathevon H, et al. Harvest of cortico-cancellous intramedullary femoral bone graft using the Reamer-Irrigator-Aspirator (RIA). Orthopaedics \& Traumatology Surgery \& Research 2012;98(2):227-32. 
[24] Porter RM, Liu F, Pilapil C, et al. Osteogenic potential of reamer irrigator aspirator (RIA) aspirate collected from patients undergoing hip arthroplasty. Journal of Orthopaedic Research 2009;27(1):42-9.

[25] Tuli R, Seghatoleslami MR, Tuli S, et al. A simple, highyield method for obtaining multipotential mesenchymal progenitor cells from trabecular bone. Molecular Biotechnology 2003;23(1):37-49.

[26] Sagi HC, Young ML, Gerstenfeld L, et al. Qualitative and quantitative differences between bone graft obtained from the medullary canal (with a Reamer/Irrigator/Aspirator) and the iliac crest of the same patient. J Bone Joint Surg Am 2012;94(23): 2128-35.

[27] Cox G, McGonagle D, Boxall SA, et al. The use of the reamer-irrigator-aspirator to harvest mesenchymal stem cells. J Bone Joint Surg Br 2011;93(4):517-24.

[28] Kirkpatrick JS, Cornell CN, Hoang BH, et al. Bone void fillers. J Am Acad Orthop Surg 2010;18(9):576-9.

[29] Arrington ED, Smith WJ, Chambers HG, et al. Complications of iliac crest bone graft harvesting. Clin Orthop Relat Res 1996;(329):300-9.

[30] Chapman PG, Villar RN. The bacteriology of bone allografts. J Bone Joint Surg Br 1992;74(3):398-9.

[31] Goldberg VM, Stevenson S. Natural history of autografts and allografts. Clin Orthop Relat Res 1987;(225):7-16.
[32] Westrich GH, Geller DS, O'Malley MJ, et al. Anterior iliac crest bone graft harvesting using the corticocancellous reamer system. J Orthop Trauma 2001;15(7):500-6.

[33] Banwart JC, Asher MA, Hassanein RS. Iliac crest bone graft harvest donor site morbidity. A statistical evaluation. Spine (Phila Pa 1976) 1995;20(9):105560 .

[34] Summers BN, Eisenstein SM. Donor site pain from the ilium. A complication of lumbar spine fusion. J Bone Joint Surg Br 1989;71(4):677-80.

[35] Goulet JA, Senunas LE, DeSilva GL, et al. Autogenous iliac crest bone graft. Complications and functional assessment. Clin Orthop Relat Res 1997;(339):76-81.

[36] Sacchetti B, Funari A, Michienzi S, et al. Self-renewing osteoprogenitors in bone marrow sinusoids can organize a hematopoietic microenvironment. Cell 2007;131(2):324-36.

[37] Bais M, McLean J, Sebastiani P, et al. Transcriptional analysis of fracture healing and the induction of embryonic stem cell-related genes. PLoS One 2009;4(5):e5393.

[38] Wise JK, Sena K, Vranizan K, et al. Temporal gene expression profiling during rat femoral marrow ablation-induced intramembranous bone regeneration. PLoS One 2010;5(10). pii: e12987. 